There is, however, no established 'target figure' for monotherapy in mentally handicapped epileptic patients. Both our surveys suggest that more can be done to reduce the number of drugs that each patient receives. The problem with the newer drugs, that are marketed as 'adjuncts', is that it can take some time to evaluate the effectiveness of the new drug. There can, therefore, be a delay in weaning such patients off their previous medication, so that for a period of time they receive three anti-epileptic drugs.

The second survey shows an encouraging trend with the reduction in the use of phenytoin and the barbituates.

Not surprisingly, serum levels of anti-epileptic drugs are monitored much less frequently in general practice. Of the patients studied by Hartropp (1987) $21 \%$ had had drugs levels recorded in a five year period. This figure is comparable to the number of our hospital patients who had not had drugs levels recorded in a three year period.

Pellock \& Wilmore (1991) comment that blood monitoring in otherwise healthy and asymptomatic patients receiving anti-epileptic drugs is not necessary. However, they also observe that "patients unable to communicate or without any advocate must be managed differently. Although data is not available, we recommend blood monitoring on an annual basis for multiply handicapped institutionalised patients. Such monitoring should minimally include basic haematology and chemistry".

The blood monitoring undertaken after the first survey was, by any standard, very thorough.
There were, however, relatively few abnormalities discovered by this general screening. Most of the 'abnormalities' were biochemical in nature, with values just outside the 'normal' reference range. There was little in the way of clinical symptoms and signs and, apart from the use of thyroxine and the investigation of the single case of irondeficiency anaemia, none of the 'abnormalities' required any treatment.

Such monitoring entails considerable expenditure and, on the basis of this survey, we feel that there is little justification for annual monitoring in the mentally handicapped.

\section{References}

BRodIE, M.J. (1990) Established anti-convulsants and treatment of refractory epllepsy, Lancet, 336, 350-354.

FISCHBACHER, E. (1982) Effect of reduction of anticonvulsants on well-being. British Medical Journal, 285, 423-424.

GunNAWAY, D.J. \& MAWER, G.E. (1981) Transfer from multiple to single AED therapy. Lancet, 1, 217.

HALL W.H. \& RosS. D. (1986) General practice study of the care of epileptic patients. The Practitioner, 230, 661-665.

HARTROPP, P. (1987) Audit of epilepsy management in a group practice. Update. 1 February 1987. 229-303.

PELLOCK. J.M. \& WILMORE. L.J. (1991) Rational guide to routine blood monitoring. Neurology, 41, 961-964.

PiRmohamed, M. (1990) Prescribing in epilepsy. The Practitioner, 234, 1070-1072.

PRESLEY, P. (1989) An audit of epilepsy in general practice. The Practitioner, 233, 1009-1014.

A.S.P. Amaladoss, Registrar; and $M$. Arumainayagam, Consultant Psychiatrist, Coldeast Hospital, Sarisbury Green, Southampton, SO3 6ZD

\title{
Guide for contributors to the Audit section
}

Audit should be a circular process. Standards are agreed, a service is surveyed against the standards, a strategy is proposed to improve quality and the service is resurveyed to assess change. The strategies which produce change in one place will often be applicable to services elsewhere. The publication of an audit should therefore contribute to the general improvement of services.

By contrast, a survey of a service frequently produces results which are specific to that place and reflect its geographical and social situation and the local provision of services. While the results may be of great interest locally, they are not applicable elsewhere.

The Psychiatric Bulletin welcomes papers describing a completed audit cycle for publication in the Audit section. Simple surveys of services are not acceptable. 